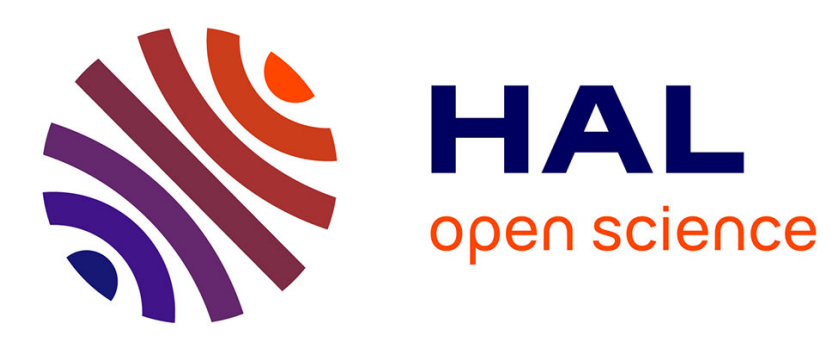

\title{
How to teach interdisciplinary: case study for Product Design in Assistive Technology
}

Guillaume Thomann, Fabio Morais, Christine Werba

\section{To cite this version:}

Guillaume Thomann, Fabio Morais, Christine Werba. How to teach interdisciplinary: case study for Product Design in Assistive Technology. 7th Int. Joint Conf. on Mechanics, Design Engineering and Advanced Manufacturing, JCM, Sep 2016, Catane, Italy. hal-01912312

\section{HAL Id: hal-01912312 https://hal.science/hal-01912312}

Submitted on 5 Nov 2018

HAL is a multi-disciplinary open access archive for the deposit and dissemination of scientific research documents, whether they are published or not. The documents may come from teaching and research institutions in France or abroad, or from public or private research centers.
L'archive ouverte pluridisciplinaire HAL, est destinée au dépôt et à la diffusion de documents scientifiques de niveau recherche, publiés ou non, émanant des établissements d'enseignement et de recherche français ou étrangers, des laboratoires publics ou privés. 


\title{
How to teach interdisciplinary: case study for Product Design in Assistive Technology
}

\author{
Guillaume THOMNN ${ }^{1,2^{*}}$, Fabio MORAIS ${ }^{3}$ and Christine WERBA ${ }^{3}$ \\ ${ }^{1}$ Univ. Grenoble Alpes, G-SCOP, F-38000 Grenoble, France \\ ${ }^{2}$ CNRS, G-SCOP, F-38000 Grenoble, France \\ ${ }^{3}$ Authors two and three affiliation \\ * Corresponding author. Tel.: +33 4768270 24; fax: +33 4765746 95. E-mail address: \\ guillaume.thomann@grenoble-inp.fr
}

\begin{abstract}
In the medical field, Assistive Technologies (AT) are one of the most dynamic due to the evolution of the population (elderly and disable people). Dedicated products are complex to design and to manufacture because of the end users' specificities and particularities. The integration of multiples competencies in the design process are necessary to be able to define a complete list of requirements. This collaborative work with the involvement of the end user necessitate a reflection about the design method. Statistics of products abandonments illustrate the difficulty for companies to create a favorable working environment taken into account multiple parameters from various expertise.

Based on these states of difficulties, the present study aims to develop an interdisciplinary experimented teaching situation focused on the use of Rapid Prototyping. The AT field has been chosen to develop this design process teaching. The favorable pedagogic context takes place in the Industrial Department of the Federal University of Paraiba. The proposal was to implicate several departments from this university to organize a complete course with the objective to teach Interdisciplinary in graduation level in the university: the initial idea was to give all necessary resources to the groups of students (two types of progressive workshop during the course); they choose the ones that are necessary to design and prototype something adapted to the user's requirements.
\end{abstract}

Keywords: Interdisciplinary, Assistive Technology, User Centered Design, Design Methodology, Teaching Product Design 


\section{Introduction}

In more and more cases, products have to be developed in collaboration between actors from several professional domains. In these cases, we spoke about interdisciplinary. The medical field is a typical context where various actors have to work together to elaborate a common list of requirements. Around the final user or a group of user, the aim of the design team is to create a favorable collaborative environment for the development of the complex product or system. The collaboration between actors from different disciplines can be facilitated by the use of specific tools and collaborative management strategies. One difficulty along the whole development process is to maintain the motivations of all the actors; another is to combine the different objectives into one unique requirements list. These daily issues constitute some challenges for professionals in industries. The rule of the universities is to prepare future managers to this complex and realistic situation. Students in the universities are always more interesting by the medical field and the innovations linked to this area. Surgical robotics, new technologies for rehabilitation, Smart materials and products like MEMS (Micro Electro Mechanical Systems) or Lab one Chip, connected devices, etc. are some examples that prove the increase of the medical market and justify the students' motivations. The objective of the paper is to share experience about the organization of an interdisciplinary course proposed in the university. It allow students to meet professors and health professionals from lots of disciplines in a design process context. The proposed study aims to imagine and propose a design process that motivate students from various engineering departments to experiment tools, methodologies and practices user oriented.

\subsection{Design Methodologies}

The field explored in the present case study is about design methodology for products in assistive technology (AT). Especially in this specific domain, final products have to match perfectly to the user requirements. They gave several benefits to people in difficult situations but research studies showed many problems with AT products abandonments [1]. The most common is the acceptance of the own limitation problem. The second reason is about the product itself. The characteristics identified concerning the product are cost to purchase and to maintain, durability, reliability, ease of use and transport, safety, efficiency and aesthetics. And lastly, researchers listed four others factors as (1) change in the needs of the user, (2) ease of purchase, (3) device performance and (4) consideration of user opinion in the selection process. Others researchers have analyzed seventeen projects carried out by students designing for and with disabled children [2]. In this situation, a coding scheme was built based on a review of the literature. This was then im- 
proved through direct observation of the design reports. After analysis of the reports, three groups have been sorted: managing interactions with the disabled children, difficulties with respect to evolving user needs and identifying the children's relevant abilities.

One the one hand the products never satisfy disabled users, one the other hand the design process is not easy to understand and to apply. The user centered approach has the objective to improve the usability of the product as a quality factor for disabled users. The User Centred Design (UCD) methodology provides five points the design project has to take into account: knowledge of end users (tasks, environments), an active participation of users (needs and requirements), the appropriate repartition of functions between users and technology, an iterative approach to design, the intervention of a multidisciplinary team [3]. The usercentered design cycle is broken down into six steps. This is an iterative process which ends when the design solution meets the requirements of the end user [4]. Prototypes have to be used to create interactions between students' groups and the users.

\subsection{Design and rapid prototyping}

The complexity of current problems requires that design process adapt to current demands. Multidisciplinary and participatory designs are a trend without return. The Top-down approach in which designers created their solutions and delivered to users is replaced by the Bottom-up approach. Users should be involved since the beginning of the design process. Not just in the testing phase. At last, as quoted [5], "The design is a participatory process in which the designer makes a partnership with problem owners (customer, user, etc.)."

Experts working disconnectedly, with different goals in so far timelines and following logics that are not concatenated properly, and not communicate with each other. "Every expert has a limited object-world, with assumptions, rules and particular goals. They see the design object of different ways, according to the pragmatic core of their discipline" [6]. Although, he mentions that "the objectworlds divide the design in different but not unrelated kinds of efforts." It implies that whatever the object to be designed, it cannot be thought like a simple overlap of technical systems. It is necessary integrating different parts. For this, the process actors should coordinate each other seeking a set of representations and making a shared context of logics [7][8]

Working in design using intermediate objects is fundamental. They allow to achieve this logic joint and a leveling ideas. The term Rapid Prototyping generally refers to prototype build methods using additive systems [9]. The time is minimal among the appearance of a possible solution and its transformation into something tangible, material. It is just the time to $3 \mathrm{D}$ printer receives the digital model and transform raw material into a product. The field of possibilities broadens enough. 
Prototyping in the medical field has enabled anticipate both usability and functionality tests [10] [11] [12].

Thus, users of assistive technology products can interact with ideas, even before being completed or manufactured in scale. Benefits are (1) to decrease design errors or inadequacies (2) a greater acceptance of end-users, (3) the possibility to quickly remake a product or modify it or to incorporate something that has been proposed by anyone involved in the project.

Facilitating the involvement of the final users (musicians and disabled children) in the design process using rapid prototyping technology has been shown by [13]. The proposition was to use several rapid prototyping technology in function of the objective to demonstrate and the process phase. Classical machining, z-printer, and two types of Fused Deposition Modelling (FDM) have been used during the developing process.

To resume, the design for and with final users imposes specific tools and methodologies. The user is rarely unique. One essential step in the beginning is identifying the variety of users once the final product in final environmental situation of use. From this state, professors' objective is to learn an optimal design process to students. It implies the knowledge of the users, the participation of experts from various disciplines, and the control of the technology used for rapid prototyping. In the paper, authors present an experimentation in the Technological Center of the Federal University of Paraiba (CT/UFPB), Brazil. This inter departments course was organized by three professors which allow groups of students to develop some AT products in optimal conditions.

\section{Course Construction and objective}

The main objectives of the course was the opportunity to meet professors and students from others disciplines in a design process context. The responsible of this course entitled "Metodologia de Projeto Multidisciplinar focado em Tecnologia Assistiva" ("Methodology of Multidisciplinary Project focused on Assistive Technology" in English) wanted to break disciplines barriers between departments.

During the three months duration of the course, all the participants share experiences with people from others departments during their product development process. This context is a necessity in AT development. Moreover, the rapid prototyping technology (FDM 3D-Printer) and one dedicated expert student were available every time in each step of the project. All the groups have one product to design and develop in relation with one or more users. Each group was constituted of several students and professors from different departments.

The methodological approach taught to students was a combination of UCD approach, iterative design, Scenario Based Design and tools from ergonomics like activity analysis. Moreover, to better understand the users' needs, the use of rapid prototyping was practically imposed. 


\section{Application: "Methodology of Multidisciplinary Project focused on Assistive Technology"}

The initial proposal in building multidisciplinary teams to solve problems related to Assistive Technology was given by two professors from ergonomics and Industrial Engineering (CT/UFPB - Brazil) and one from Mechanical Engineer (Grenoble University - France).

This proposal of an exceptional course for all volunteers from the UFPB exceeds administrative barriers. The professors obtained agreements from many engineering departments, medical department and doctoral school. This allowed the concrete formations of heterogeneous group: level of formation and disciplines (Table 1). Five groups of 8 to 9 students were structured.

Table 1. Participants list of the course.

\begin{tabular}{|l|c|c|c|c|c|}
\hline Discipline & Professors & $\begin{array}{c}\text { Master thesis } \\
\text { students }\end{array}$ & $\begin{array}{c}\text { Graduate } \\
\text { students }\end{array}$ & Graduated & Total \\
\hline Industrial Engineering (IE) & 02 & 09 & 06 & & 17 \\
\hline Mechanical Engineering (ME) & & & 02 & & 02 \\
\hline Design (Des) & 02 & 03 & 03 & & 08 \\
\hline Ocupacional Therapy (OT) & 02 & 01 & & & 03 \\
\hline Phisioterapy (Physio) & 03 & 02 & 10 & & 15 \\
\hline Architecture (Archi) & & 01 & & 01 & 02 \\
\hline Informatics (Info) & 01 & 01 & & & 02 \\
\hline TOTAL & 11 & 17 & 21 & 01 & 50 \\
\hline
\end{tabular}

The course was divided into 11 weeks. Each week should contain brief presentations on relevant topics to the projects (main workshops), and also interaction times in group. Each meeting lasted about 4 hours. At these meetings, the project groups should proceed with the project, according to the expertise of each participant in the group.

All course participants were classified according to their graduation course. A balanced distribution between the groups was promoted. Groups have been constituted based on some criteria: project motivation, expertise, formation level, discipline. One of the main objectives of the course was achieved, the multidisciplinary. Unfortunately, each discipline could not be represented within the groups.

Before the first meeting, the students and professionals were invited to propose one product that could be developed. Projects have been chosen based on some criteria: presence and participation of user(s), possibility to prototype quickly, necessity of a multidisciplinary project team. Moreover, the unique focus was to design and develop an AT product. Many people showed demands that were already 
in development. Others brought unknown needs or not yet studied ones. As might be expected, the demands emerged, largely, from health professionals. At least one user participated to each design project.

Some experts have been identified. They constitute the staff of the course. They have been defined not only because of their expertise maturity but also because of the lack of competencies compared to the number of projects. Their rules were to help all groups, depending of their needs. The areas of expertise are: ergonomics, quality, ethics, digital modeling and rapid prototyping.

These weekly workshops have been mainly given by the defined experts. They served to leveling on some important issues in AT area. The first two workshops were giver by professors:

- Introduction of the course: Objectives, methodology, organisation, explanation of the workshops and the rules of the experts. Choice of the projects and the groups.

- Presentation from professors of each department: design methodologies used with user's involvement or not, examples in AT or not.

Others workshops have been presented to share knowledge in complementary areas. All along the design process and depending of the projects main phases, the experts proposed interventions about UCD iterative methodologies, activity analysis, quality, management, rapid prototyping and CAD software, patents, ethics and scientific valorisation. The activity analysis has been taught and practically directly applied on the situation case with the supervision of the ergonomics professor. The time management was in the responsible of each group and the first meeting with the health professional and the user have allowed to clarify the design goals.

\section{Results}

After the course, each group held a final presentation in which the projects objectives, the methods and techniques used in the product development and the experienced difficulties were described. Time was a factor that hampered the good development of some projects as well as the dependency on the users' participation. Some groups were dependent on the free times of observed users. However, all groups reached a result. Concepts of the product were designed and sometimes prototyped. All of them meet the objectives established initially. The table 2 shows the main results that have been observed and discussed between the professors responsible of the course.

Table 2. Projects' Main results.

\begin{tabular}{|c|c|c|}
\hline Product and Main goal & Methods and techniques used & Problems encountered \\
\hline $\begin{array}{c}\text { Building device that performs } \\
\text { the pressure measurement of }\end{array}$ & Activity Analysis. & The understanding was hard by \\
the cuff external steadily in pa- & underwent tracheostomy. & technological experts. A previ- \\
tient underwent tracheostomy & Prototyping with alternative & was required for engineers and \\
\hline
\end{tabular}




\begin{tabular}{|c|c|c|}
\hline $\begin{array}{c}\text { Creating tablet support by indi- } \\
\text { viduals without coordination of } \\
\text { upper limbs and who use } \\
\text { wheelchair }\end{array}$ & $\begin{array}{c}\text { materials. } \\
\text { Direct observations of disabled } \\
\text { people using tablets. Digital } \\
\text { modeling and rapid prototyping }\end{array}$ & $\begin{array}{c}\text { de-signers. } \\
\text { neering. The mechanical design } \\
\text { feeling could help in making } \\
\text { other concepts. }\end{array}$ \\
\hline $\begin{array}{c}\text { Designing device to independ- } \\
\text { ent neatness (individual clean- } \\
\text { ing) after do physiological } \\
\text { needs }\end{array}$ & $\begin{array}{c}\text { Activity Analysis. Digital mod- } \\
\text { eling and prototyping (alterna- } \\
\text { tive materials and ABS plastic) }\end{array}$ & $\begin{array}{c}\text { Observing end-users in perform- } \\
\text { ing the task was so hard. A short } \\
\text { time to prototyping and testing. }\end{array}$ \\
\hline $\begin{array}{c}\text { Designing a packaging opener } \\
\text { that helps people with upper } \\
\text { limbs disabilities. }\end{array}$ & $\begin{array}{c}\text { Activity Analysis. Digital mod- } \\
\text { eling and sketches making }\end{array}$ & $\begin{array}{c}\text { There was impossibility to make } \\
\text { functional prototypes due the } \\
\text { absence of constructive mechan- } \\
\text { ical elements }\end{array}$ \\
\hline $\begin{array}{c}\text { Developing a toy that enables } \\
\text { that children with cerebral pal- } \\
\text { sy playing. }\end{array}$ & $\begin{array}{c}\text { Activity Analysis. Survey with } \\
\text { disabled people and their ca- } \\
\text { reers. Usability testing with } \\
\text { functional prototype }\end{array}$ & $\begin{array}{l}\text { High diversity between the char- } \\
\text { acteristics of cerebral palsy peo- } \\
\text { ple. Limitations of Sphero con- } \\
\text { trol software. }\end{array}$ \\
\hline
\end{tabular}

According to broad multidisciplinary construction of groups, different methodologies were followed. Techniques, tools and models were used according to the expert's areas or situations that were emerged. No patterns were required.

Prototypes were used by almost all groups. The used way was different between them. The 3D printer was not used by every groups. The projects needed an initial understanding of the relationship users have with the prototype. In the case of tracheostomy, the prototype had to be tested to various users in different situations. The choice of a prototype made of alternative materials was due to the need of transportability. The Sphero Soccer already has a part of the solution. What remained to be designed was the site for Sphero's use related to needs of disabled user. Thus, the choice of alternative materials was due to the paucity of ideas.

The groups in which there were more professionals in technical areas (Engineering and Design) followed more specific and detailed steps with more restrictive decision gates. It is noticed that the project progress to these groups was more linear than other groups that are using more iterative methodologies.

A learned lesson became apparent at all groups. Dealing with people from different areas in the same project is not simple. Specific phases are necessary to share tools and techniques from all the experts.

\section{Observations and discussions}

Two main profiles were identified for a better project progress: project management and health professional. Each group was independent and used tools and technics they need in their context. The negative feedbacks were about (1) the lack of time (10 weeks) to realise the project, (2) the poor anticipation with ethics comity for working with patients, (3) sometimes the number of members per group, (4) the difficulty to meet users from others departments and to organize others 
meetings during the week. The point highlighted was the presence of health professionals to interact with the user in the context of use. Despite of the difficulty to evaluate benefits for students, all of they effectively used learnt tools and experimented user interaction with prototypes and activity analysis.

\section{Conclusion}

To mix health professionals, disabled user, students and professors from different engineering departments and is a challenge. With the objective to teach interdisciplinary, applying design methods and using tools from various disciplines is essential. Moreover students' motivation is a key factor. Teaching on a real case to promote users' interactions can be and adequate context answering these criteria.

\section{References}

1. Phillips B., M.S. and Zhao H., Predictors of Assistive Technology Abandonment, Assistive Technology, Vol 5, pp.36-451, 1993

2. Magnier C., Thomann G., Villeneuve F., Seventeen Projects carried out by Students Designing For And With Disabled Children: Identifying Designers' Difficulties During The Whole Design Process, Assistive Technology, Vol 24, Issue 4, pp. 273-285, 2012

3. ISO 9241-210.: International Organization for Standardization. Ergonomics of human-system interaction -- Part 210: Human-centred design for interactive systems, 2010

4. Ma, M.-Y., Wu, F.-G., and Chang, R.-H., A new design approach of user-centered design on a personal assistive bathing device for hemiplegia. Disabil Rehabil 29, 1077-1089, 2009

5. SIMON, Herbert A. The sciences of the artificial. 3.ed. MIT Press: Cambridge, 1996. 215p.

6. BUCCIARELLI, Louis L. Designing and learning: a disjunction in contexts. Design Studies, v.24, n3, 2003b.

7. WILKINSON, Christopher R. Applying user centred and participatory design approaches to commercial product development. Design Studies 35 (2014) pp.614-631

8. TOH Christine A. and MILLER, Scarlett R. How engineering teams select design concepts: A view through the lens of creativity. Design Studies 38 (2015) pp. $111-138$

9. BUSWELL, R.; SOAR R.; GIBB A.; THORPE A. Freeform Construction: Mega-scale Rapid Manufacturing for construction. In: Automation in Construction 16, 2007, p.224-231

10. Zhang, S., et al. Application of Rapid Prototyping for Temporomandibular Joint Reconstruction, American Association of Oral and Maxillofacial Surgeons. Elsevier Inc. All rights reserved, 2011

11. SHEREKAR, Rahul M. \& PAWAR, Anand N. Application of biomodels for surgical planning by using rapid prototyping: a review \& case studies. International Journal of Innovative Research in Advanced Engineering (IJIRAE) ISSN: 2349-2163 Volume 1 Issue 6 (July 2014)

12. NEGI, Sushant; DHIMAN, Suresh; SHARMA, Rajesh Kumar, (2014) "Basics and applications of rapid prototyping medical models", Rapid Prototyping Journal, Vol. 20 Iss: 3, pp.256 $-267$

13. Justine Coton, Marcel de Gois Pinto, Julien Veytizou, Guillaume Thomann, Design for disability: Integration of human factor for the design of an electro-mechanical drum stick system, 24th CIRP Design Conference, Abril 14-16, Milano, Italy, 2014 